\title{
Cyclic Behavior of Substandard Reinforced Concrete Beam-Column Joints with Plain Bars
}

\author{
by Catarina Fernandes, José Melo, Humberto Varum, and Aníbal Costa
}

\begin{abstract}
An experimental investigation aimed at assessing the cyclic behavior of substandard interior beam-column joints built with plain reinforcing bars is described in this paper. Five specimens with plain reinforcing bars and one with deformed bars were tested under reversed cyclic loading. The influence of bond properties, displacement history, column axial load, and amount of reinforcement was investigated. A comparison was established in terms of maximum strength, damage, energy dissipation, ductility, displacement components, and rotation capacity. Better bond properties led to a more spread damage distribution and larger energy dissipation. Higher column axial load resulted in larger lateral strength and energy dissipation. A larger amount of longitudinal and transverse reinforcement did not necessarily lead to enhanced behavior. The test results contribute to the characterization of the cyclic behavior of beam-column joints with plain bars and can be used to calibrate numerical models for the simulation of this type of element.
\end{abstract}

Keywords: beam-column joints; bond slip; cyclic behavior; full-scale tests; plain reinforcing bars; reinforced concrete.

\section{INTRODUCTION}

Reinforced concrete (RC) structures built until the mid1970s, before the introduction of modern seismically oriented codes, were usually designed for gravity loads only. As a consequence of the absence of any capacity design principles in design and poor reinforcement details, a significant lack of ductility - at both the local and global levels-is expected for these structures, resulting in inadequate structural performance even under moderate seismic excitations. ${ }^{1}$

Past experimental investigation and damage observed following recent earthquakes indicate that deficiencies in the detailing of beam-column joints often lead to brittle failure of the connections and, consequently, of the entire frame. Different damage or failure modes are expected to occur depending on the typology (exterior or interior joint) and adopted structural details (namely, total lack or presence of a minimum amount of transverse reinforcement in the joint, use of plain reinforcing bars or deformed bars, and alternative anchorage solutions). ${ }^{2}$

Numerous experimental studies have investigated the cyclic behavior of RC beam-column joints. However, relatively few experimental investigations are focused on the behavior of joints with design details typical of pre-1970s $\mathrm{RC}$ structures. Among these, the majority refer to joints with deformed bars. ${ }^{3-5}$ There is a significant lack of information about the cyclic behavior of beam-column joints built with plain reinforcing bars, which were widely used for longitudinal reinforcement in structures built before the 1970s and are characterized by low bond properties.

Examples of recent experimental studies on the cyclic behavior of RC beam-column joints with plain reinforcing bars can be found in References 1, 3, and 6 through 10 .
Liu and Park $^{6}$ tested the response of full-scale beamcolumn joints designed according to the pre-1970s codes. The main test variables were the manner in which the longitudinal beam bars were hooked in the joint core and the level of the column axial load. Similar units using deformed bars were also tested. In comparison to the specimens with deformed bars, the specimens with plain bars displayed significantly lower stiffness and strength, less joint shear distortion but high opening of beam bar hooks in tension, and column bar buckling. Pampanin et al. ${ }^{1}$ tested four exterior and two interior 2/3-scaled beam-column joints designed for gravity loads only and characterized by the absence of transverse reinforcement in the joint and poor anchorage detailing. Two different types of anchorage solutions for the beam longitudinal reinforcement through the joint region were considered in the interior joints' specimens: continuous reinforcement or lapped splices with hooked-end anchorage outside the joint region. A better global joint behavior was obtained for the specimens with lapped splices and hookedend anchorage. The bar-slip phenomenon was evidenced by the marked pinching of the hysteresis.

Bedirhanoglu et al. ${ }^{3}$ tested full-scale exterior corner beamcolumn joints with plain reinforcing bars and low-strength concrete. The sensitivity of the specimens' behavior to column axial load, displacement history, amount of joint reinforcement, presence of a transverse beam and a transverse slab, and conditions of anchorage within the joint was investigated. The test results show that an increase in column axial load led to less pinching of the hysteresis loops and an increase in the dissipated energy. The influence of displacement history was negligible. The use of transverse reinforcement in the joint resulted in larger lateral strength capacities and energy dissipation capacity. The presence of the transverse beam and slab resulted, in general, in larger lateral load.

The experimental work described herein refers to the cyclic tests performed on six full-scale beam-column joints, representative of interior beam-column joints of existing RC building structures designed without adequate reinforcement detailing for seismic loading. Five specimens were built with plain reinforcing bars and one specimen was built with deformed bars to allow a performance comparison to be established. The sensitivity of the specimens' behavior to bond properties, displacement history, column axial load, and amount of steel reinforcement was investigated.

ACI Structural Journal, V. 110, No. 1, January-February 2013

MS No. S-2011-088.R1 received April 13, 2011, and reviewed under Institute publication policies. Copyright (C) 2013, American Concrete Institute. All rights reserved, including the making of copies unless permission is obtained from the copyright proprietors. Pertinent discussion including author's closure, if any, will be published in the November-December 2013 ACI Structural Journal if the discussion is received by July 1,2013 
Catarina Fernandes is a PhD Student at the University of Aveiro, Aveiro, Portugal. Her research interests include assessment and strengthening of existing building structures.

José Melo is a PhD student at the University of Aveiro. His research interests include assessment and strengthening of existing building structures.

Humberto Varum is an Associate Professor in the Civil Engineering Department at the University of Aveiro. His research interests include assessment, strengthening, and repair of existing structures; structural testing and modeling; and earth construction.

Aníbal Costa is a Full Professor in the Civil Engineering Department at the University of Aveiro. His research interests include rehabilitation and strengthening of structures and seismic engineering.

\section{RESEARCH SIGNIFICANCE}

The available data on the cyclic behavior of substandard $\mathrm{RC}$ beam-column joints built with plain reinforcing bars are less rich and detailed when compared to those for joints with deformed bars. The behavior of this type of element under cyclic loading is not yet comprehensively understood. The experimental investigation described in this paper will contribute to enlarging the available database on substandard beam-column joints with plain reinforcing bars. The experimental results presented can be used to upgrade and calibrate numerical models for the adequate simulation of the cyclic behavior of this type of element.

\section{Test specimens}

\section{EXPERIMENTAL INVESTIGATION}

The specimens were designed to represent an interior beam-column connection. Each column element represents a half-story column in a building, and each beam element represents a half-span beam. Five specimens (JPA-1, JPA-2, JPA-3, JPB, and JPC) were built with plain reinforcing bars and one specimen (JD) was built with deformed bars. The geometry, dimensions, and reinforcement detailing of the test specimens are depicted in Fig. 1. In all specimens, beam and column longitudinal reinforcement was continuous, there was no transverse reinforcement in the joint region, and stirrups in the beams and columns had 90-degree hooks. Longitudinal and transverse reinforcement ratios, computed according to Eurocode 2 (EC2), ${ }^{11}$ are summarized in Table 1, where: 1) $\rho_{l, \text { beam }}$ is the total longitudinal reinforcement ratio in the beam; 2) $\rho_{l, \text { column }}$ is the total longitudinal reinforcement ratio in the column; 3 ) $\rho_{w \text {, beam }}$ is the ratio of the transverse reinforcement in the beam; and 4) $\rho_{w, \text { column }}$ is the ratio of the transverse reinforcement in the column. The steel reinforcement amount and detailing adopted in Specimens JPA-1, JPA-2, and JPA-3 are referred to in this work as standard reinforcement.

The flexural and shear capacities of the beams and columns (considering the axial load) were computed according to $\mathrm{EC} 2^{11}$ and are indicated in Table 2 . The flexural capacity of
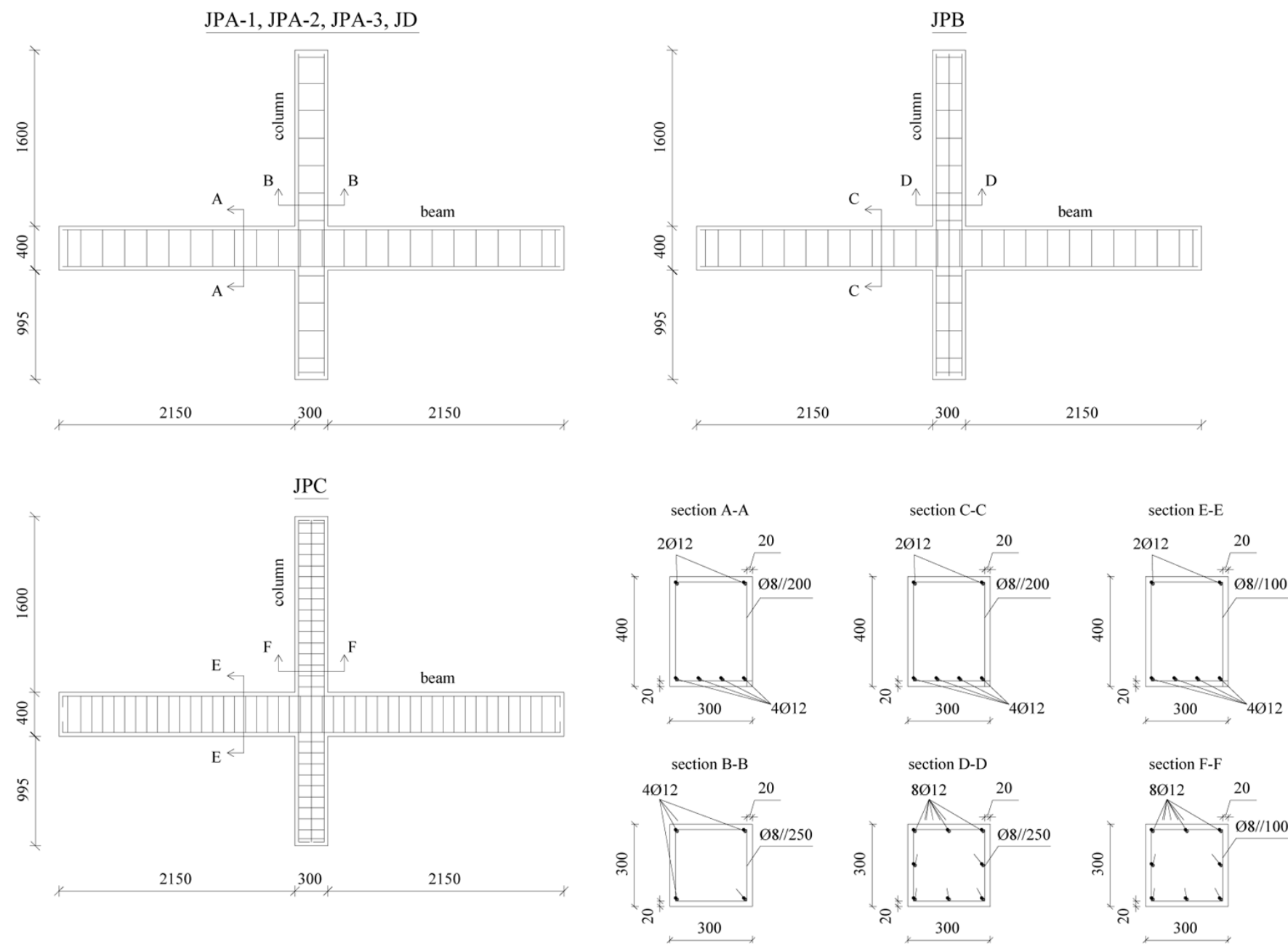

Note: Dimensions are in millimeters $(\mathrm{mm}) .1 \mathrm{~mm}=0.0394$ in
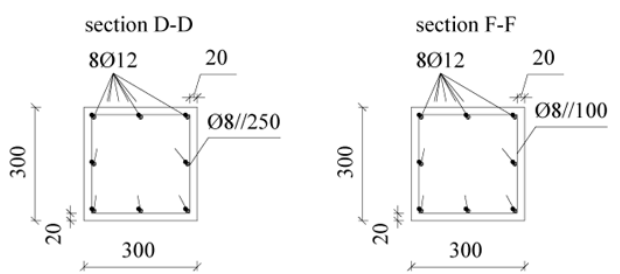

Fig. 1-Geometry, dimensions, and reinforcement detailing of test specimens. 


\begin{tabular}{|c|c|c|c|c|c|c|c|c|c|}
\hline \multirow[b]{3}{*}{ Specimen } & \multirow[b]{3}{*}{ Steel } & \multicolumn{4}{|c|}{ Beam } & \multicolumn{4}{|c|}{ Column } \\
\hline & & \multicolumn{2}{|c|}{ Longitudinal reinforcement } & \multicolumn{2}{|c|}{ Transverse reinforcement } & \multicolumn{2}{|c|}{ Longitudinal reinforcement } & \multicolumn{2}{|c|}{ Transverse reinforcement } \\
\hline & & $\begin{array}{l}\text { Diameter, } \\
\text { mm (in.) }\end{array}$ & $\rho_{l, \text { beam }}, \%$ & $\begin{array}{l}\text { Diameter, } \\
\text { mm (in.) }\end{array}$ & $\rho_{w, \text { beam }}, \%$ & $\begin{array}{c}\text { Diameter, } \\
\text { mm (in.) }\end{array}$ & $\rho_{l, \text { column }}, \%$ & $\begin{array}{l}\text { Diameter, } \\
\text { mm (in.) }\end{array}$ & $\rho_{w, \text { column }}, \%$ \\
\hline JPA-1 & Plain bars & \multirow{6}{*}{$12(0.47)$} & 0.6 & \multirow{6}{*}{$8(0.32)$} & 0.17 & \multirow{6}{*}{$12(0.47)$} & 0.5 & \multirow{6}{*}{$8(0.32)$} & 0.13 \\
\hline JPA-2 & Plain bars & & 0.6 & & 0.17 & & 0.5 & & 0.13 \\
\hline JPA-3 & Plain bars & & 0.6 & & 0.17 & & 0.5 & & 0.13 \\
\hline JPB & Plain bars & & 0.6 & & 0.17 & & 1.0 & & 0.13 \\
\hline JPC & Plain bars & & 0.6 & & 0.34 & & 1.0 & & 0.34 \\
\hline JD & Deformed bars & & 0.6 & & 0.17 & & 0.5 & & 0.13 \\
\hline
\end{tabular}

Table 2-Flexural and shear capacities of beams and columns computed according to Eurocode $2^{11}$

\begin{tabular}{|c|c|c|c|c|c|}
\hline \multirow[b]{2}{*}{ Specimen } & \multicolumn{3}{|c|}{ Flexural capacity, kN (kips) } & \multicolumn{2}{|c|}{ Shear capacity, kN (kips) } \\
\hline & Positive direction & Negative direction & Column & Beam & Column \\
\hline JPA-2 & $48(11)$ & $25(6)$ & $40(9)$ & $244(55)$ & $142(32)$ \\
\hline JPA-3 & $48(11)$ & $25(6)$ & $62(14)$ & $244(55)$ & $142(32)$ \\
\hline JPC & $48(11)$ & $25(6)$ & $92(21)$ & $488(110)$ & $354(80)$ \\
\hline $\mathrm{JD}$ & $36(8)$ & $19(4)$ & $40(9)$ & $178(40)$ & $103(23)$ \\
\hline
\end{tabular}

the elements is indicated in terms of the corresponding lateral load. Note that the formulation included in $\mathrm{EC} 2^{11}$ considers the plane cross-section assumption and perfect bond conditions between steel and concrete. Hence, for elements with plain reinforcing bars, the empirical procedure included in $\mathrm{EC} 2^{11}$ may not accurately estimate their behavior.

\section{Materials}

All specimens were cast on the same day and with the same concrete mixture. Compressive tests on concrete $0.15 \times 0.15 \times 0.15 \mathrm{~m}(5.9 \times 5.9 \times 5.9$ in. $)$ cubic samples, cast together with the specimens, were conducted to determine the concrete compressive strength. A mean strength equal to $23.8 \mathrm{MPa}$ (3.45 ksi) was obtained. The characteristic compressive strength estimated is equal to $19.8 \mathrm{MPa}$ (2.87 ksi), corresponding to the $\mathrm{C} 16 / \mathrm{C} 20$ concrete class according to the $\mathrm{EC} 2^{11}$ classification.

The mean mechanical properties of the steel longitudinal reinforcement are indicated in Table 3. The strength of the plain reinforcing bars is higher than the typical values for this type of steel reinforcement in existing buildings. However, considering that the cyclic behavior of the elements is strongly influenced by the concrete-steel bond properties, the steel strength is not expected to influence the specimens' response significantly.

\section{Test setup and loading pattern}

Figure 2 illustrates the test setup that was adopted, indicating the idealized support and loading conditions, and the schematics adopted for the linear variable displacement transducers (LVDTs) used for measuring the local relative displacements in the beam-joint and column-joint interfaces (Slice 1) and vicinities (Slice 2) and joint. The specimens
Table 3-Steel mechanical properties (mean values)

\begin{tabular}{c|c|c}
\hline Characteristics & Plain bars & Deformed bars \\
\hline Yielding strength, MPa (ksi) & $590(86)$ & $430(62)$ \\
\hline Ultimate strength, MPa (ksi) & $640(93)$ & $550(80)$ \\
\hline Elastic modulus, GPa (ksi) & $198(28,717)$ & $200(29,008)$ \\
\hline
\end{tabular}

were tested in the horizontal position. Four high-loadcarrying capacity devices with reduced friction were placed below the specimens to carry their self-weight. Steel reaction frames associated to sliding devices at the beam extremities and to a pinned connection at the base of the column were used to simulate the support conditions. The maximum frictional forces in the devices used to carry the specimens' self-weights and to simulate the supports at beams were less than $2.5 \%$ of the corresponding lateral load imposed.

The test was conducted under displacement-controlled conditions. Two hydraulic actuators were arranged at the top of the superior column: one to impose the lateral displacements $d_{c}$ and the other for the axial load $N$. Two levels of axial load were considered: $200 \mathrm{kN}$ (45 kips) in Specimens JPA-1, JPA-2, and $\mathrm{JD}$, corresponding to a normalized axial load equal to $9.4 \%$, and $450 \mathrm{kN}$ (101 kips) in Specimens JPA-3, JPB, and JPC, corresponding to a normalized axial load equal to $21.3 \%$. A displacement history constituted by a series of push-and-pull cycles (three cycles for each level of drift imposed) with a total of 18 levels up to a 4\% drift was imposed on all specimens except JPA-2. In the displacement history imposed on JPA-2, only one push-and-pull cycle was performed for each level of drift, with a total of seven levels up to a $4 \%$ drift. 


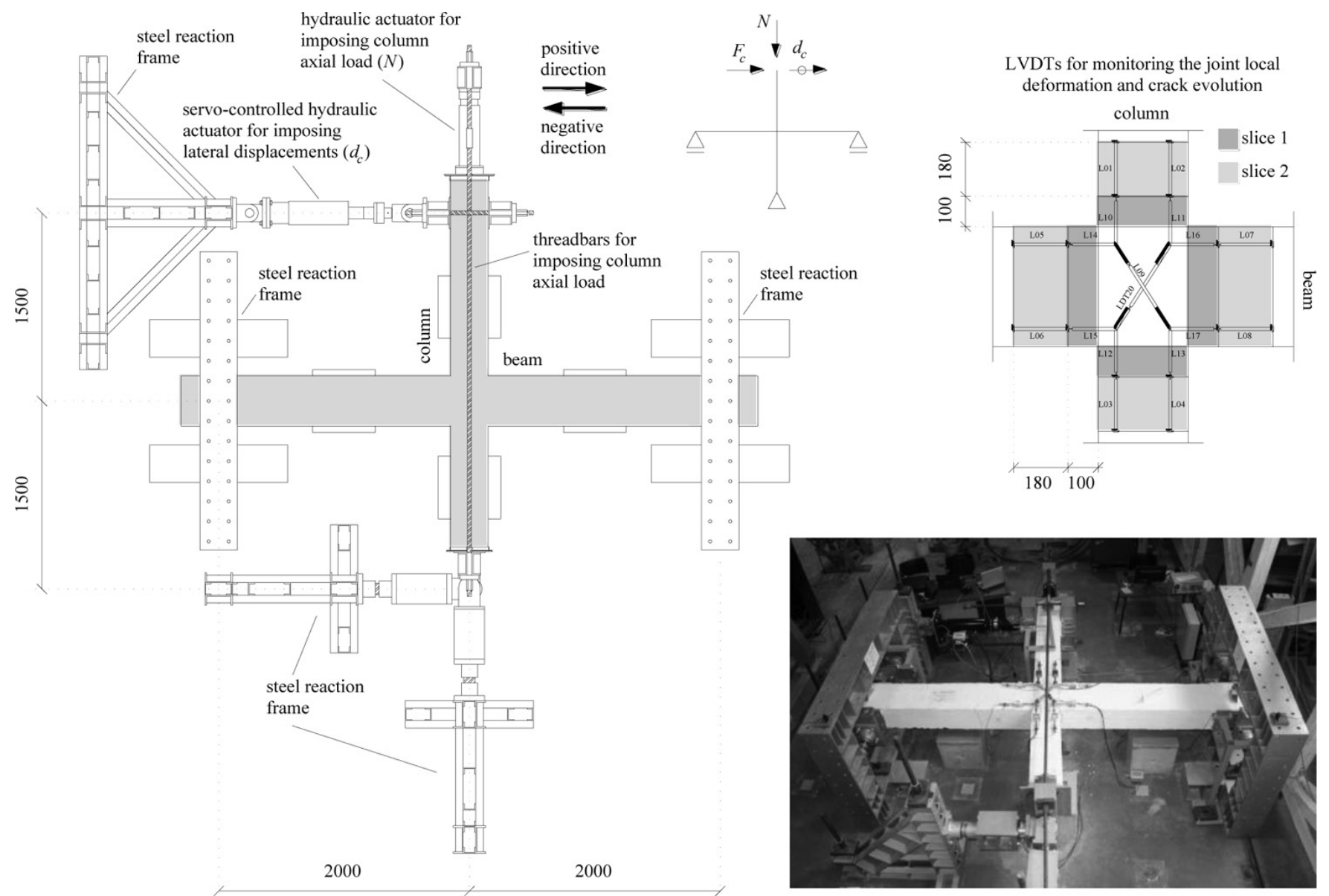

Note: Dimensions are in millimeters $(\mathrm{mm}) .1 \mathrm{~mm}=0.0394 \mathrm{in}$.

Fig. 2-Test setup.

\section{EXPERIMENTAL RESULTS AND DISCUSSION Lateral-load-versus-drift diagrams}

Figure 3 presents the experimental results in terms of lateral load versus imposed drift. Each plot represents the curves obtained for two different specimens for a better understanding of the influence of the variable parameter in question on the specimens' global behavior, namely: bond properties (JPA-1 versus JD), displacement history (JPA-1 versus JPA-2), column axial load (JPA-1 versus JPA-3), and amount of steel reinforcement (JPA-3 versus JPB and JPA-3 versus JPC).

Table 4 summarizes the values of the maximum lateral load $F_{c, \max }$ achieved by each specimen and the corresponding drift, the yielding displacement $\Delta_{y}$ (computed according to Annex B.3 of Eurocode 8: Part $\left.1\left[\mathrm{EC} 8-1^{12}\right]\right)$, and the strength degradation registered at the maximum imposed drift (computed in relation to $F_{c, \text { max }}$ ).

For each specimen, the maximum lateral load reached in the positive and negative loading directions is similar. The specimen with deformed bars reached the lateral strength at a lateral drift inferior to that observed for the specimens with plain reinforcing bars. The specimens with plain reinforcing bars reached the lateral strength at similar drift levels. Within the drift range imposed on the specimens, JPA-3 displayed the greatest strength and also the largest strength degradation. In fact, the failure condition usually adopted, corresponding to a strength reduction of $20 \%$ with respect to the peak resistance, was only registered for Specimen JPA-3 at a drift between 3.7 and $4 \%$. The differences registered between maximum lateral load and strength degradation are welldepicted by the lateral load-drift peak envelopes in Fig. 3(f). The pinching effect was observed for all specimens, being less important for the specimen with deformed bars and more evident in the responses of Specimens JPB and JPC.

Comparing the maximum moment demand in each element with the corresponding capacity predicted according to $\mathrm{EC} 2^{11}$ (Table 2), it is concluded that: 1) for the specimen with deformed bars, EC2 provides a good estimate of the elements' strength, overestimating the beams' strength by $10 \%$ and underestimating the columns' strength by $2 \%$; and 2) for all the specimens with plain reinforcing bars, the EC2 expressions overestimate the capacity of the elements by approximately 10 to $30 \%$.

\section{Damage observed and damage index}

Figure 4 illustrates the crack pattern corresponding to the final damage state of the specimens. In general terms, the specimens with plain reinforcing bars displayed damage concentrated at the beam-joint and column-joint interfaces within Slice 1. Damage within Slice 2 was, in most cases, negligible. From Slice 2 to the end of the elements' length, damage was not observed. Specimen JPA-3 displayed significant damage within the joint region with concrete cover spalling. In Specimens JPB and JPC, damage was heavily concentrated at the beam-joint interfaces, while cracking at the column-joint interfaces was minor. Conversely to what 


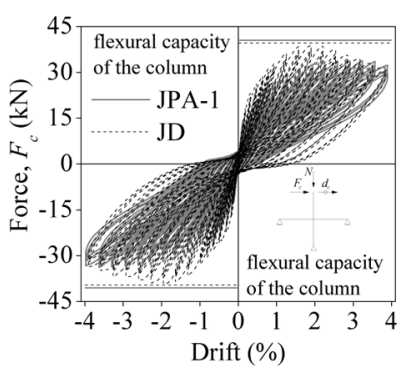

(a)

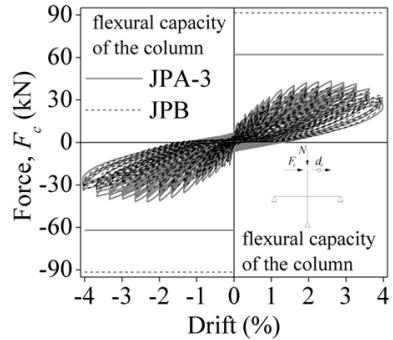

(d)

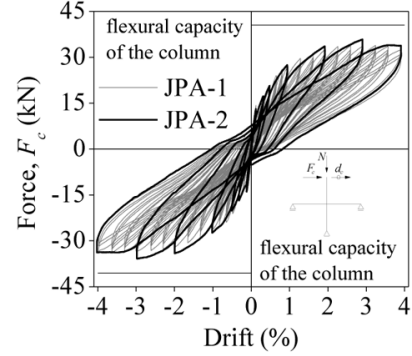

(b)

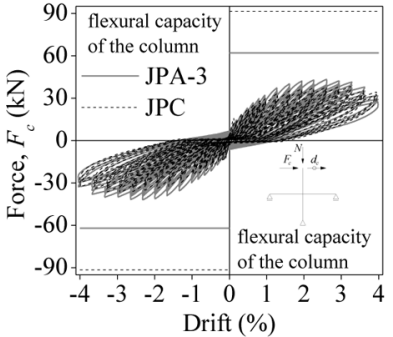

(e)

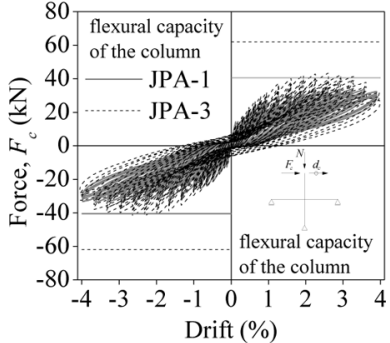

(c)

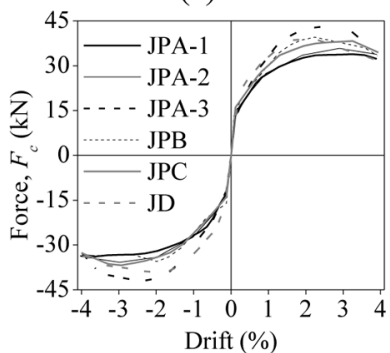

(f)

Fig. 3-Lateral-load-versus-drift responses for specimens: (a) JPA-1 versus JD; (b) JPA-1 versus JPA-2; (c) JPA-1 versus JPA-3; (d) JPA-3 versus JPB; (e) JPA-3 versus JPC; and (f) peak envelopes. (Note: $1 \mathrm{kN}=0.2248$ kips.)

Table 4-Maximum lateral load, yielding displacement, and strength degradation

\begin{tabular}{c|c|c|c|c}
\hline \multirow{2}{*}{ Specimen } & \multicolumn{2}{|c|}{ Maximum lateral load } & \multirow{2}{*}{$\Delta_{y}, \mathrm{~mm}(\mathrm{in})}$. & Strength degradation at $4 \%$ drift, $\%$ \\
\cline { 2 - 5 } & $F_{c, \text { max }}, \mathrm{kN}(\mathrm{kips})$ & Drift, $\%$ & $28.2(1.11)$ & 4.5 \\
\hline JPA-1 & $34.0(7.6)$ & 3.3 & $28.2(1.11)$ & 5.8 \\
\hline JPA-2 & $35.8(8.0)$ & 3.0 & $31.1(1.22)$ & 26.6 \\
\hline JPA-3 & $43.3(9.7)$ & 2.7 & $26.0(1.02)$ & 15.8 \\
\hline JPB & $39.5(8.9)$ & 2.3 & $27.0(1.06)$ & 10.0 \\
\hline JPC & $38.3(8.6)$ & 3.3 & $23.8(0.94)$ & 19.0 \\
\hline JD & $39.0(8.8)$ & 2.0 & & \\
\hline
\end{tabular}

was observed for the specimens with plain reinforcing bars, the specimen with deformed bars displayed a more spread damage distribution. Cracking was spread along the beam and column lengths and severe cracking with concrete cover spalling was observed within the joint region. Due to the stiffness degradation associated with the damage evolution, a small reduction in the column axial load was registered for all specimens, with a maximum variation ranging from $2.8 \%$ (for JPB) to $10.3 \%$ (for JPA-3).

Table 5 indicates the drift at which the first flexural cracks and inclined cracks (within the joint region) were registered. In all specimens, the flexural cracks were first observed in the beams at or close to the interface with the joint region at drifts ranging from 0.07 to $0.20 \%$. Cracking onset at the column-joint interfaces was registered for higher drift levels ranging from 0.33 to $2 \%$. The maximum crack widths registered at the beam-column and joint-column interfaces are also indicated in Table 5.

The maximum value estimated for the principal tensile stress developed in the joint region is equal to $0.32 f_{c}^{0.5}$ for Specimen JPA-1, $0.35 f_{c}^{0.5}$ for JPA-2, $0.31 f_{c}^{0.5}$ for JPA-3, $0.26 f_{c}^{0.5}$ for JPB, $0.25 f_{c}^{0.5}$ for JPC, and $0.39 f_{c}^{0.5}$ for JD $\left(f_{c}\right.$ is the concrete compressive strength). Although Specimens JPA-1 and JPA-3 were tested with different column axial load, they developed similar maximum stress in the joint.
However, while in JPA-1 (with lower axial load), cracking was not observed in the joint, in JPA-3, diagonal cracking occurred at the drift corresponding to the maximum principal tensile stress. Larger column longitudinal reinforcement (JPB and JPC) reduced the maximum principal tensile stress by $16 \%$.

The Park and Ang (PA) damage index ${ }^{13}$ was computed for Specimens JPA-1 and JD (plain reinforcing bars versus deformed bars) for each level of imposed drift. The column properties were considered to estimate the parameters involved in the computation. The time evolution of the PA damage index is depicted in Fig. 5 and 6, together with the contribution of the maximum deformation $u_{\max } / u_{u}$. For the first levels of imposed drift-up to $1 \%$ - the average contribution of the maximum deformation to the PA damage index was equal to $99 \%$ for the two specimens. For the last three levels of imposed drift, the average contribution was approximately $82 \%$ and $80 \%$ for JPA- 1 and JD, respectively. The results show the relatively minor contribution of the energy dissipation to the PA damage index, which was also observed by Varum. ${ }^{14}$

Figures 5 and 6 show the damage state categories suggested by Park et al. ${ }^{15}$ and the corresponding global damage indexes boundaries (refer to Reference 14). For each specimen, Fig. 5 and 6 also indicate the drift corre- 
sponding to the onset of the main types of damage observed in the experimental tests, namely: cracking at the beamjoint and column-joint interfaces, diagonal cracking in the joint region, and concrete cover spalling in the beams and columns. In both specimens, cracking onset occurred within the expected range of the global damage index. Concrete cover spalling was registered for damage indexes larger than those suggested. The drift at which the specimens reach each damage state is, in general, lower for the specimen with plain reinforcing bars than for the specimen with deformed

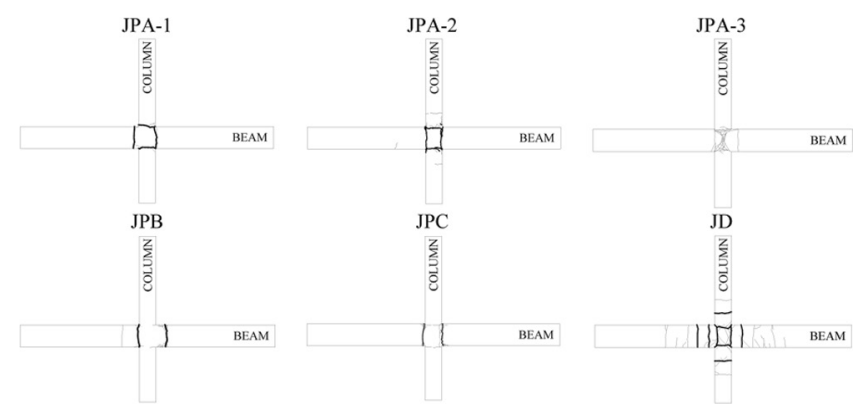

Fig. 4-Crack pattern corresponding to final damage state. bars. For example, a damage index equal to 1 is registered for a drift of $3 \%$ for JPA-1 and $3.3 \%$ for JD.

\section{Energy dissipation and ductility demands}

In Fig. 7, the evolution of the total dissipated energy, computed as the area under the lateral load-drift diagrams, is plotted for all specimens except JPA-2. Specimen JPA-2 was excluded from this analysis because it was subjected to a displacement history different from the one imposed on the other specimens. The largest energy dissipation was registered for Specimens JPA-3 (with higher column axial load) and JD (with better bond properties). The pronounced pinching effect observed in the lateral load-drift diagrams of Specimens JPB and JPC led to significantly lower energy dissipation in comparison to JPA-3 (subjected to the same displacement history and column axial load).

Figure 8(a) shows a plot of the response of each specimen in terms of equivalent damping versus displacement ductility. For Specimens JPA-1, JPA-3, and JD, the curves that best fit the experimental results are also presented. Specimen JPA-2 was also excluded from this analysis. Equivalent damping $\xi_{e q}$ was computed according to Varum $^{14}$ as the ratio between the dissipated energy for half the load-displacement cycle and the viscous damping for the corresponding maximum drift. Displacement ductility

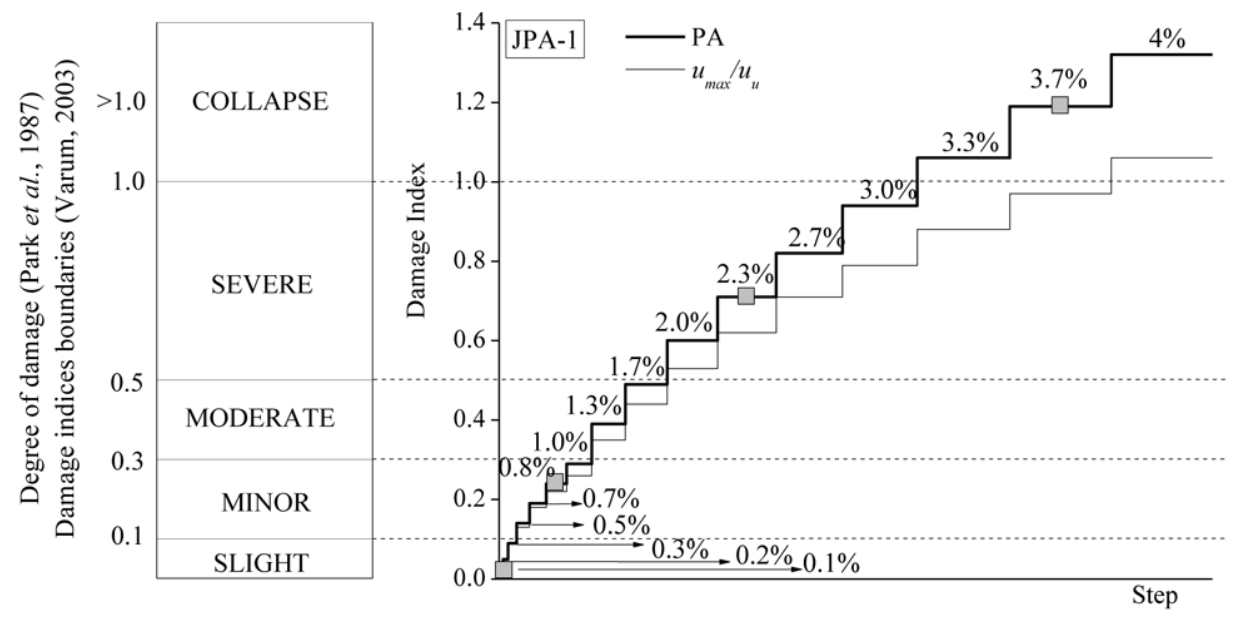

$\square$ Damage evolution

$\mathbf{0 . 0 7 \%}$ drift: cracking onset at the right beam-joint interface $\quad \mathbf{0 . 1 3} \%$ drift: cracking onset at the left beam-joint interface $\mathbf{0 . 8 3} \%$ drift: cracking onset at the superior column-joint and inferior column-joint interfaces

$\mathbf{2 . 3 3} \%$ drift: onset of concrete cover spalling in the beams $\quad \mathbf{3 . 6 7 \%}$ drift: onset of concrete cover spalling in the columns

Fig. 5-Time evolution of PA damage index for Specimen JPA-1.

Table 5-Drift corresponding to cracking onset

\begin{tabular}{c|c|c|c|c|c}
\hline \multirow{2}{*}{ Specimen } & \multicolumn{4}{|c|}{ Flexural cracks } & \multirow{2}{*}{ Drift at first inclined crack within joint region, \% } \\
\cline { 2 - 5 } & Drift at first crack, $\%$ & Maximum crack width, mm (in.) & - \\
\hline JPA-1 & 0.07 & Column & Beam & Column & - \\
\hline JPA-2 & 0.13 & 0.83 & $5.9(0.23)$ & $5.9(0.23)$ & - \\
\hline JPA-3 & 0.13 & 1.33 & $6.9(0.27)$ & $3.1(0.12)$ & 2.67 \\
\hline JPB & 0.20 & 2.00 & $12.4(0.49)$ & $0.1(0.004)$ & - \\
\hline JPC & 0.13 & 1.67 & $12.2(0.48)$ & $0.3(0.001)$ & 4.00 \\
\hline JD & 0.13 & 0.33 & $5.4(0.21)$ & $10.4(0.41)$ & 0.67 \\
\hline
\end{tabular}




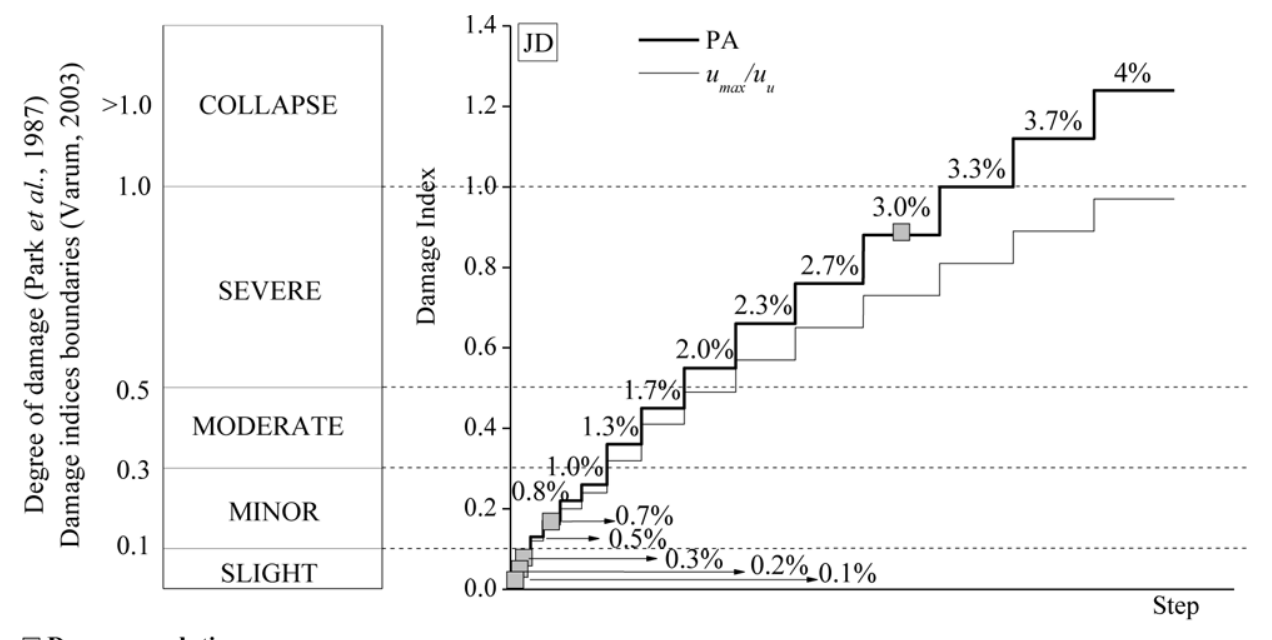

$\square$ Damage evolution

$\mathbf{0 . 1 3} \%$ drift: cracking onset at the right beam-joint interface $\quad \mathbf{0 . 2 0} \%$ drift: cracking onset at the left beam-joint interface $\mathbf{0 . 3 3} \%$ drift: cracking onset at the superior column-joint and inferior column-joint interfaces

$\mathbf{0 . 6 7 \%}$ drift: cracking onset in the joint region $\quad \mathbf{3 . 0 0} \%$ drift: onset of concrete cover spalling in the columns

Fig. 6-Time evolution of PA damage index for Specimen JD.

$\mu_{\Delta}$ corresponds to the ratio between imposed displacement $d_{c}$ and yielding displacement $\Delta_{y}$ (Table 4). Within the drift range under analysis, the largest and lowest ductility demands were imposed on JD $\left(\mu_{\Delta}=5.0\right)$ and JPA-3 $\left(\mu_{\Delta}=\right.$ 3.8). Even if the lowest demand, in terms of ductility, was imposed on JPA-3, it is recalled that this was the only specimen that reached the conventional failure condition.

Figure 8(b) shows a comparison between the experimental results and the equivalent damping-versus-displacementductility relationships computed from some of the existing equivalent damping equations, ${ }^{16}$ namely: Eq. (1), proposed by Priestley ${ }^{17}$ for concrete frames, and Eq. (2), referring to the Takeda model. ${ }^{18}$ This comparison is made considering that existing RC building structures built without adequate seismic detailing tend to develop soft story mechanisms and therefore the response of the beam-column joints of a weak story may be correlated to the response of the overall structure. In addition, a comparison is also made with the equivalent damping computed from Eq. (3), proposed by Varum, ${ }^{14}$ based on the results of a series of pseudo-dynamic tests of an RC frame structure built with plain reinforcing bars.

$$
\begin{aligned}
& \xi=5+\frac{120}{\pi} \cdot\left(1-\frac{1}{\sqrt{\mu_{\Delta}}}\right) \\
& \xi=\xi_{0}+0.2 \cdot\left(1-\frac{1}{\sqrt{\mu_{\Delta}}}\right) \\
& \xi=11.041 \cdot \ln (\Delta)+9.9286
\end{aligned}
$$

In Eq. (2), $\xi_{0}$ is the initial viscous damping (considered equal to $5 \%$ ). In Eq. (3), $\Delta$ represents the interstory drift.

The equivalent damping-displacement ductility relationships determined from Eq. (1) to (3) significantly overes-

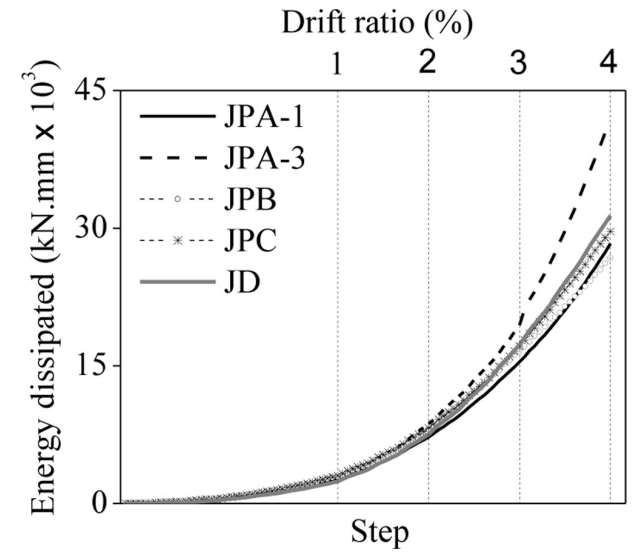

Fig. 7-Evolution of total dissipated energy. (Note: $1 \mathrm{kN.mm}$ $=8.85$ lbf $\cdot$ in .)

timate the experimental results. Equations (1) and (2) are more adequate for structures with larger energy dissipation capacities. This highlights the need for the development of simplified expressions, based on experimental data, for the assessment of existing RC building structures built without specific seismic detailing and, in particular, with plain reinforcing bars. Regarding Eq. (3), the experimental results used for determining the equivalent damping-displacement ductility relationship refer to a particular story. In these tests, the story response was mainly governed by the behavior of a strong column. Conversely to what was observed in the joint specimens with plain reinforcing bars under study, damage in that strong column was not concentrated at the interface with the joint. Instead, it was spread along a larger element's plastic hinge region. Hence, the associated energy dissipation is expected to be larger than that displayed by the beamcolumn joints under study.

\section{Drift components}

This section studies the relative contribution of beam and column deformations to the specimen deformation. The direct integration method was used for estimating the total 


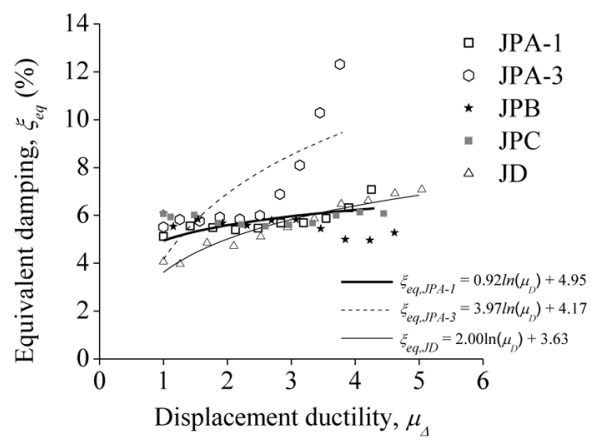

(a)

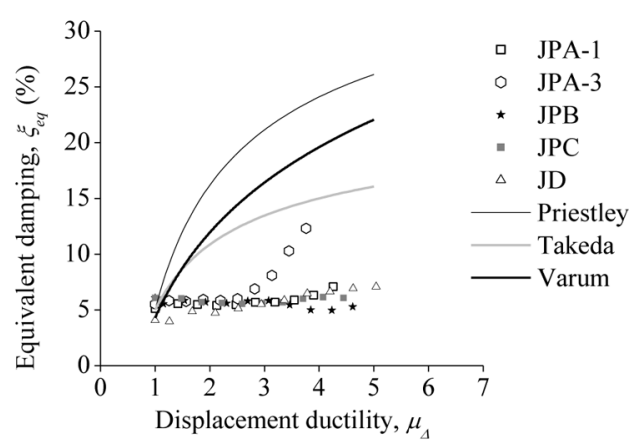

(b)

Fig. 8-Equivalent damping versus displacement ductility: (a) experimental results; and (b) comparison with results of existing equivalent damping equations.

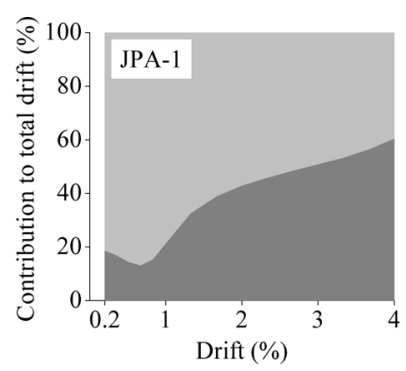

(a)

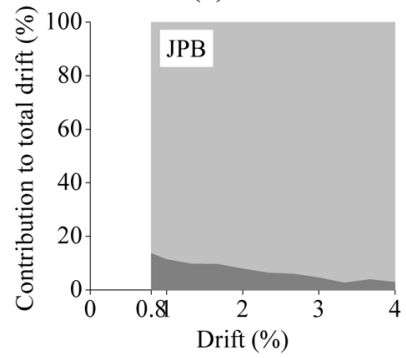

(d)

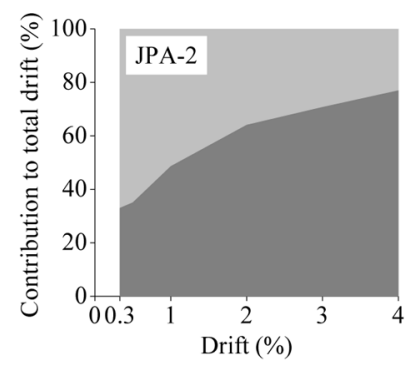

(b)

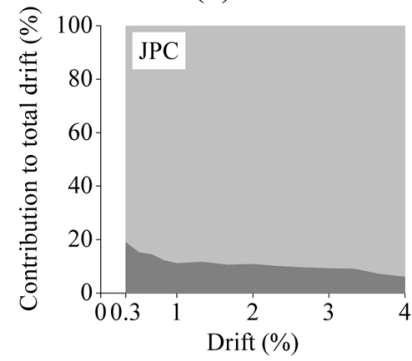

(e)

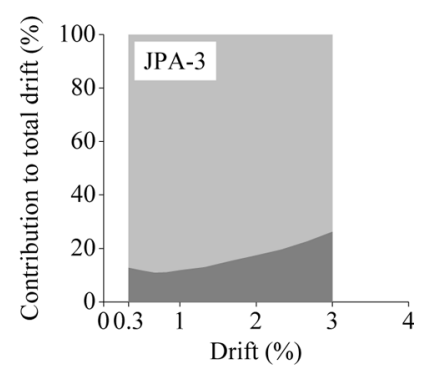

(c)

nColumns

Beams

Fig. 9-Relative partial contribution of beams and columns to total drift in specimens: (a) JPA-1; (b) JPA-2; (c) JPA-3; (d) JPB; and (e) JPC.

drift and the contribution of each component. Considering the concentration of damage observed in the specimens with plain reinforcing bars and assuming a linear distribution of moments along the beam and column lengths, the curvature distribution in each element was analytically established. Thus, in the analytical formulation, the following assumptions are made for the curvatures of each element (refer to the nomenclature in Fig. 2): a linear variation from the element extremity (where the curvature is zero) to the interface between Slices 1 and 2, and a parabolic variation between this section and the interface between Slice 1 and the joint (where the maximum curvature occurs). In the calculations, the mean curvatures measured in Slices 1 and 2 were used as input in the analytical expressions derived. Considering the assumptions previously presented, the direct integration method was used for determining the deflection and rotation along the elements.

Based on the analytical equations for each element, and considering the compatibility conditions in terms of displacements and rotation at the joint, as well as the displacement restraints at the supports, the deformation equations for all the specimens were obtained.
With the expressions derived, the lateral displacement at the free end of the superior column was determined at each time step and compared to the corresponding experimental values. In general terms, a good match was found between the experimental and analytical results. The maximum difference registered between the experimental and analytical displacements was: $8 \%$ for JPA-1, 7\% for JPA-2, $15 \%$ for JPA-3, $19 \%$ for JPB, and 9\% for JPC. Therefore, the analytical equations were used for determining the contribution of each element to the total lateral displacement, which is proportional to the lateral drift. The relative contribution of beams and columns to the total drift imposed on the specimens with plain reinforcing bars is represented in Fig. 9.

The curvature distribution adopted for the elements with plain reinforcing bars does not represent the damage displayed by the specimen with deformed bars. Furthermore, the experimental results in terms of curvature (measured in Slices 1 and 2) are not sufficient for a precise definition of the curvature distribution in this specimen; therefore, the specimen with deformed bars was excluded from this analysis.

For all specimens, the results show that at lower imposed drift levels, the beam deformation controls the total drift 
associated with the deformation of the specimens. For Specimens JPA-1, JPA-2, and JPA-3, as the imposed lateral drift increases, the contribution of column deformation to the total drift rises. Conversely, in Specimens JPB and JPC, the contribution of column deformation decreases with the imposed drift. These results are in accordance with the damage evolution registered during the testing of each specimen. At a 3\% drift, the relative contribution of the column deformation to the total drift is equal to $51 \%$ for JPA-1, $71 \%$ for JPA-2, 26\% for JPA-3, 5\% for JPB, and 9\% for JPC.

\section{Ultimate rotation capacity}

Eurocode 8: Part 3 (EC8-3) ${ }^{19}$ evaluates the deformation capacity of RC elements in terms of the chord rotation. For elements with plain reinforcing bars, the ultimate rotation capacity is evaluated by applying a correction coefficient (always inferior to 1), based on experimental data, to the capacity formulations calibrated on elements with deformed bars and seismic detailing. For elements without lapping of the longitudinal bars, the correction coefficient is equal to 0.575 . According to Verderame et al., ${ }^{20}$ some provisions of EC8-3 have been changed according to Reference 21 and the correction coefficient has been increased to 0.80 . In either case, according to the code provisions, the ultimate rotation capacity of elements with plain reinforcing bars is smaller than that of elements with deformed bars with equivalent structural characteristics and details. However, recent experimental results ${ }^{20,22}$ indicate the contrary. According to Verderame et al., ${ }^{23}$ when plain reinforcing bars are used, chord rotation results from a combined action of the fixedend rotation at the base and spreading of yielding over the element length. A critical review of the EC8-3 approach for estimating the ultimate rotation capacity of elements with plain reinforcing bars is made by Verderame et al. ${ }^{20}$ Based on the test results from recent experiments on RC columns with plain reinforcing bars, the authors also propose a new correction coefficient to be applied to the EC8-3 expressions. For elements without lapping of longitudinal bars, the proposed correction coefficient is equal to 1.0.

To make a comparison between the ultimate rotation capacity predicted by EC8-3 and the one estimated from the experimental results for the specimens under study, joint rotation had to be subtracted from the total drift imposed on the specimens so that the columns' chord rotation could be obtained. Joint rotation was estimated by the direct integration method used for determining the displacement components. For the reasons previously stated, Specimen JD was excluded from the analysis. Specimen JPA-3 was also excluded from this analysis because, for drift levels superior to $3 \%$, the direct integration method did not provide a good match between the experimental and analytical results. Hence, maximum column chord rotation could not be determined for this specimen.

Table 6 presents the theoretical values of ultimate rotation capacity computed using the EC8-3 expression and multiplied by the correction coefficient. Three correction coefficients were considered: 1) the correction coefficient prescribed by EC8-3, equal to 0.575 ; 2) the new EC8-3 correction coefficient, equal to 0.80 according to Verderame et al. $^{20}$; and 3 ) the correction coefficient proposed by Verderame et al. ${ }^{20}$ equal to 1.0. Accordingly and respectively, three different theoretical values of ultimate rotation capacity are presented for each specimen: $\theta_{u, E C 8}, \theta_{u, E C 8}^{\prime}$, and $\theta_{u, \text { Verd }}$.
Table 6-Theoretical values of ultimate rotation capacity

\begin{tabular}{c|c|c|c}
\hline \multirow{2}{*}{ Specimen } & \multicolumn{3}{|c}{ Ultimate rotation capacity, \% } \\
\cline { 2 - 4 } & $\theta_{u, E C 8}$ & $\theta_{u, E C 8}^{\prime}$ & $\theta_{u, \text { Verd. }}$ \\
\hline JPA-1 & 1.98 & 2.75 & 3.44 \\
\hline JPA-2 & 1.98 & 2.75 & 3.44 \\
\hline JPB & 1.72 & 2.39 & 2.99 \\
\hline JPC & 1.83 & 2.55 & 3.18 \\
\hline
\end{tabular}

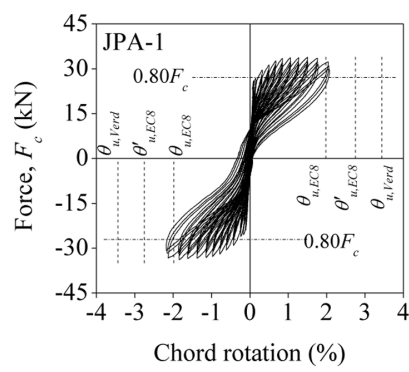

(a)

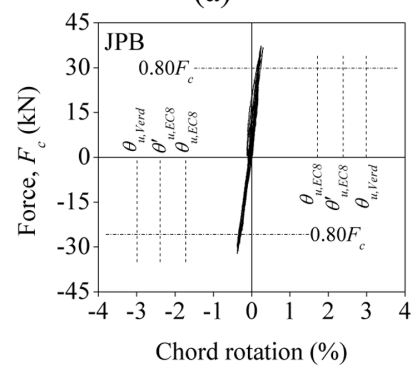

(c)

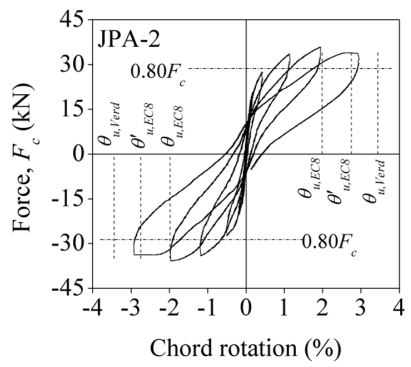

(b)

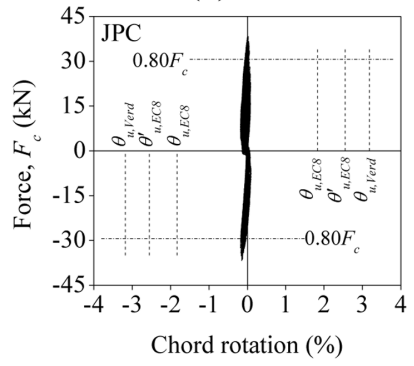

(d)
Fig. 10-Lateral-load-versus-column chord rotation relationships for specimens: (a) JPA-1; (b) JPA-2; (c) JPB; and (d) JPC. (Note: $1 \mathrm{kN}=0.2248$ kips.)

Figure 10 shows the lateral load-column chord rotation diagrams obtained for the specimens under analysis, with indication of the failure condition for which the rotational capacity is usually evaluated (corresponding to a strength reduction of $20 \%$ with respect to the peak resistance) and the theoretical values of ultimate rotation capacity. A strength reduction equal to or larger than $20 \%$, measured in the forceversus-chord-rotation diagrams, was not registered for either of the specimens analyzed. In fact, the maximum strength reduction recorded was equal to $6 \%$ (for Specimen JPA-2). Hence, neither of the specimens reached the ultimate rotation capacity predicted by EC8-3. JPA-1 achieves the ultimate rotation capacity $\theta_{u, E C 8}$ for a strength reduction equal to $4 \%$. JPA-2 reaches $\theta_{u, E C 8}$ for its peak strength and $\theta_{u, E C 8}^{\prime}$ for a strength reduction equal to $6 \%$. For JPA-2, and considering the tendency displayed by the force-versus-column-chordrotation diagram in the last cycles, the approach proposed by Verderame et al. ${ }^{20}$ seems to give better results.

\section{Influence of bond properties}

As shown in Fig. 3(a), Specimens JPA-1 (with plain reinforcing bars) and JD (with deformed bars) displayed similar stiffness until the beginning of cracking. After cracking onset, for larger displacement demands, JPA-1 showed lower unloading stiffness than JD. The maximum lateral load registered for the specimen with 
deformed bars (at a 2\% drift) was approximately $15 \%$ higher than that for the specimen with plain reinforcing bars (at a $3.3 \%$ drift). Strength degradation at maximum drift was equal to $4.5 \%$ for JPA-1 and $19 \%$ for JD. The pinching effect was observed for both specimens but was more evident for the specimen with plain reinforcing bars. The effects of bond properties were particularly evidenced by the differences in the damage distribution (Fig. 4). The specimen with plain reinforcing bars displayed damage concentrated at the beamjoint and column-joint interfaces without damage within the joint region. The specimen with deformed bars displayed a more spread damage distribution, with cracking along the elements' lengths and significant damage within the joint region. The different damage distributions are reflected in the energy dissipation capacities of the specimens (Fig. 7). As expected, better bond properties led to larger energy dissipation. At maximum drift, the total energy dissipated by JD was $8 \%$ higher than that for JPA-1. Within the drift range imposed on the specimens, JD displayed larger ductility demands than JPA-1 (Fig. 8).

\section{Influence of displacement history}

The influence of displacement history was minor. Specimens JPA- 1 and JPA-2 displayed similar stiffness, before and after cracking, and similar maximum lateral load (reached at similar drift) and strength degradation (Fig. 3(b)). Damage distribution was also alike (Fig. 4).

\section{Influence of column axial load}

As shown in Fig. 3(c), Specimens JPA-1 (with lower column axial load) and JPA-3 (with higher column axial load) displayed similar stiffness until the beginning of cracking. After cracking onset, JPA-3 exhibited larger stiffness than JPA-1. The increase in column axial load led to an increase of approximately $27 \%$ in the maximum lateral load, which was reached for lower drift $(2.7 \%)$ than in the case of JPA-1 (at a 3.3\% drift). The specimen with higher axial load also displayed significantly greater strength degradation, reaching the conventional failure condition corresponding to a $20 \%$ strength reduction. Strength degradation at maximum drift was equal to $4.5 \%$ for JPA- 1 and $26.6 \%$ for JPA-3. The pinching effect was more evident for JPA-3. However, it practically ceases after the specimen reaches the maximum load. Damage in JPA-1 was concentrated at the beam-joint and column-joint interfaces. In JPA-3, significant damage was also observed within the joint region (Fig. 4). Increasing the column axial load resulted in larger energy dissipation (Fig. 7). At maximum drift, the total energy dissipated by JPA-3 is approximately $47 \%$ higher than that for JPA-1. Within the drift range imposed on the specimens, JPA-3 displayed lower ductility demands than JPA-1 (Fig. 8).

\section{Influence of amount of steel reinforcement}

As shown in Fig. 3(d) and (e), Specimens JPA-3 (with standard steel reinforcement), JPB, and JPC displayed similar stiffness until cracking onset. Prior to and after reaching maximum strength, JPA-3 displays the greatest stiffness. The maximum lateral load registered for Specimens JPB and JPC is approximately $91 \%$ (at a 2.3\% drift) and $88 \%$ (at a $3.3 \%$ drift), respectively, of that for JPA-3 (at a $2.7 \%$ drift). Increasing the amount of steel reinforcement resulted in lower strength degradation. At maximum drift, strength degradation was equal to $26.6 \%$ for JPA-3, $15.8 \%$ for JPB, and 10\% for JPC. The pinching effect was particularly evident for Specimens JPB and JPC. The energy dissipation associated with these two specimens is significantly lower than that registered for JPA-3 (Fig. 7). At maximum drift, the total energy dissipated by JPA-3 is approximately $56 \%$ and $41 \%$ higher than that for JPB and JPC, respectively. Within the drift range imposed on the specimens, Specimens JPB and JPC display a similar equivalent dampingdisplacement ductility relationship with larger ductility demands in comparison to JPA-3 (Fig. 8).

\section{CONCLUSIONS}

An experimental investigation was performed to assess the cyclic behavior of full-scale RC interior beam-column joints built with plain reinforcing bars and poor reinforcement detailing. Five specimens with plain reinforcing bars and one specimen with deformed bars were tested under reversed cyclic loading imposed under displacement-controlled conditions. The influence of bond properties, displacement history, column axial load, and amount of steel reinforcement was investigated. Two levels of column axial load were considered: $200 \mathrm{kN}$ (45 kips) and $450 \mathrm{kN}$ (101 kips). Two displacement histories were considered, both up to a maximum drift of $4 \%$ - one with fewer displacement cycles than the other. Among the specimens with plain reinforcing bars, in comparison to the others, one specimen was built with a larger amount of column longitudinal reinforcement and another with larger amounts of column longitudinal reinforcement and transverse reinforcement in the beams and columns.

The influence of bond properties was particularly evidenced by differences observed in the damage distribution of the specimens. In the specimens with plain reinforcing bars, damage was mainly concentrated at the beam-joint and column-joint interfaces. Conversely, a more spread damage distribution was observed in the specimen with deformed bars, with cracking along the elements' lengths and significant damage within the joint region. Better properties led to larger energy dissipation.

The effects of the column axial load were observed mainly in terms of lateral strength and damage distribution. Increasing the column axial load led to larger lateral strength and significantly greater strength degradation. In the specimen with higher column axial load, significant damage was also observed within the joint region. This specimen displayed considerably more energy dissipation.

The influence of the amount of steel reinforcement was mainly evidenced by the damage distribution. In the two specimens with larger amounts of steel reinforcement, damage was mostly concentrated at the beam-joint interfaces. Damage in the columns was minor and no damage was observed within the joint region. The energy dissipation associated with these two specimens was significantly lower than that in the specimen with standard steel reinforcement.

\section{ACKNOWLEDGMENTS}

This paper reports research developed under financial support provided by Fundação para a Ciência e Tecnologia (FCT), Portugal, co-funded by the European Social Fund within the scope of the Programa Operacional Potencial Humano (POPH) of the National Strategic Reference Framework, namely through the $\mathrm{PhD}$ grants of the first and second authors, with references SFRH/BD/27406/2006 and SFRH/BD/62110/2009, respectively. The authors would like to acknowledge the following companies: Civilria, for the construction of the test specimens; and Somague, Grupo Meneses, Silva Tavares \& Bastos Almeida and Paviútil, for the construction of the 
structural reaction systems. The authors also acknowledge $\mathrm{H}$. Pereira and A. Figueiredo for assisting in the preparation of the test.

\section{REFERENCES}

1. Pampanin, S.; Calvi, G. M.; and Moratti, M., "Seismic Behavior of RC Beam-Column Joints Designed for Gravity Loads," Paper No. 726, Proceedings of the 12th European Conference on Earthquake Engineering, London, UK, 2002, 10 pp.

2. Pampanin, S., "Alternative Performance-Based Retrofit Strategies and Solutions for Existing RC Buildings," Seismic Risk Assessment and Retrofitting, A. Ilki, F. Karadogan, S. Pala, and E. Yuksel, eds., Springer, Berlin, Germany, 2009, pp. 267-295.

3. Bedirhanoglu, I.; Ilki, A.; Pujol, S.; and Kumbasar, N., "Behavior of Deficient Joints with Plain Bars and Low-Strength Concrete," ACI Structural Journal, V. 107, No. 3, May-June 2010, pp. 300-310.

4. Clyde, C.; Pantelides, C. P.; and Reaveley, L. D., "Performance-Based Evaluation of Exterior Reinforced Concrete Building Joints for Seismic Excitation," PEER Report 2000/05, Pacific Earthquake Engineering Research Center, University of California, Berkeley, Berkeley, CA, 2000, 61 pp.

5. Pantelides, C. P.; Hansen, J.; Nadaul, J.; and Reaveley, L. D., “Assessment of Reinforced Concrete Building Exterior Joints with Substandard Details," PEER Report 2002/18, Pacific Earthquake Engineering Research Center, University of California, Berkeley, Berkeley, CA, 2002, 114 pp.

6. Liu, A., and Park, R., "Seismic Behaviour and Retrofit of Pre-1970's As-Built Exterior Beam-Column Joints Reinforced by Plain Round Bars," Bulletin of the New Zealand Society for Earthquake Engineering, V. 34, No. 1, 2001, pp. 68-81.

7. Park, R., "A Summary of Results of Simulated Seismic Loads on Reinforced Concrete Beam-Column Joints, Beams and Columns with Substandard Reinforcing Details," Journal of Earthquake Engineering, V. 6, No. 2, 2002, pp. 147-174.

8. Akguzel, U., and Pampanin, S., "Seismic Upgrading of Exterior BeamColumn Joints Using GFRP," Proceedings of the 14th European Conference on Earthquake Engineering, Paper 760, Ohrid, Republic of Macedonia, 2010. (CD-ROM)

9. Eligehausen, R.; Genesio, G.; Ožbolt, J.; and Pampanin, S., "3D Analysis of Seismic Response of RC Beam-Column Exterior Joints Before and After Retrofit," Proceedings of the 2nd International Conference on Concrete Repair, Rehabilitation and Retrofitting, Cape Town, South Africa, 2008, pp. 1141-1147.
10. Hertanto, E., "Seismic Assessment of Pre-1970s Reinforced Concrete Structure," MSc thesis, University of Canterbury, Christchurch, New Zealand, 2005, $247 \mathrm{pp}$.

11. EN 1992-1-1:2004, "Eurocode 2: Design of Concrete StructuresPart 1-1: General Rules and Rules for Buildings,' European Committee for Standardization, Brussels, Belgium, 2004, pp. 70 and 156.

12. EN 1998-1:2004, "Eurocode 8: Design of Structures for Earthquake Resistance-Part 1: General Rules, Seismic Actions and Rules for Buildings," European Committee for Standardization, Brussels, Belgium, 2004, pp. 201-202.

13. Park, Y.-J., and Ang, A. H.-S., "Mechanistic Seismic Damage Model for Reinforced Concrete," Journal of Structural Engineering, ASCE, V. 111, No. 4, 1985, pp. 722-739.

14. Varum, H., "Seismic Assessment, Strengthening and Repair of Existing Buildings," PhD thesis, University of Aveiro, Aveiro, Portugal, 2003, 546 pp.

15. Park, Y.-J.; Ang, A. H.-S.; and Wen, Y. K., "Damage-Limiting Aseismic Design of Buildings," Earthquake Spectra, V. 3, No. 1, 1987, pp. 1-26.

16. Blandon, C., and Priestley, M. N. J., "Equivalent Viscous Damping Equations for Direct Displacement Based Design," Journal of Earthquake Engineering, V. 9, No. 2, 2005, pp. 257-278.

17. Priestley, M. N. J., Myths and Fallacies in Earthquake Engineering, Revisited. The Mallet-Milne Lecture, IUSS Press, Pavia, Italy, 2003, pp. 93-115.

18. Gulkan, P., and Sozen, M. A., "Inelastic Responses of Reinforced Concrete Structure to Earthquake Motions," ACI Journal, Proceedings V. 71, No. 12, Dec. 1974, pp. 604-610.

19. EN 1998-3:2005, "Eurocode 8: Design of Structures for Earthquake Resistance-Part 3: Strengthening and Repair of Buildings," European Committee for Standardization, Brussels, Belgium, 2005, pp. 36-40.

20. Verderame, G. M.; Ricci, P.; Manfredi, G.; and Cosenza, E., "Ultimate Chord Rotation of RC Columns with Smooth Bars: Some Considerations about EC8 Prescriptions," Bulletin of Earthquake Engineering, V. 8, No. 6, 2010, pp. 1351-1373.

21. CEN, "Corrigenda to EN 1998-3, Document CEN/TC250/SC8/ N437A,' European Committee for Standardization, Brussels, Belgium, 2009.

22. Di Ludovico, M.; Verderame, G. M.; Prota, A.; Manfredi, G.; and Cosenza, E., "Experimental Investigation on Non-Conforming Full Scale RC Columns," Proceedings of the XIII Conference ANIDIS, Paper S02_09, Bologna, Italy, 2009. (CD-ROM)

23. Verderame, G. M.; Fabbrocino, G.; and Manfredi, G., "Seismic Response of R.C. Columns with Smooth Reinforcement-Part II: Cyclic Tests," Engineering Structures, V. 30, No. 9, 2008, pp. 2289-2300. 
